\title{
Soft Skills for Software Project Team Members
}

\author{
Emmanuel S. Mtsweni, Tertia Hörne, and John Andrew van der Poll
}

\begin{abstract}
Software development usually occurs in the context of software project management (SPM). An often cited challenge in the area of software project management is the high failure rate of software development projects (SPDs). One of the factors contributing to the failure of SDPs is the lack of soft issues, also known as soft skills or human aspects. The main purpose of this research was to identify and categorise the soft skills that facilitate the delivery of successful SDPs. To this end a survey was conducted in the form of a questionnaire as the research instrument. The results of the survey underwent a quantitative analysis and it was found that a variety of soft skills are important in facilitating the delivery of successful SDPs. Although a wide range of soft skills were identified, not all soft skills can be considered to be of crucial or equal importance.
\end{abstract}

Index Terms-Soft skills, software development projects, software project failure.

\section{INTRODUCTION}

Organisations use Information and Communication Technology (ICT) in order to achieve their strategic objectives and to gain a competitive advantage over their competitors. Software is one of the important components of ICT. Software is developed in the form of a project because of the advantages projects have, such as the utilisation of less financial and human resources, time saving and also a positive impact on the strategic goals of the organisation [1]. One of the priorities when developing software is to develop high quality and efficient software [2]. The biggest challenge with software development projects (SDPs) is their high failure rate [3].

The failure rate of SDPs has been high for more than a decade [4]. Their failure rate is more than the failure rate of projects in other fields and also in the field of ICT such as infrastructure [3]. It is reported that $70 \%$ of SDPs result in failure [5].

The high failure rate of SDPs results in organisations not fully benefiting from SDPs. Another disadvantage for organisations is the fact that they do not realize their return on investment (ROI) while investing heavily in ICT [6].

There are several sources of failure of SDPs that have been identified [6]. Those factors range from a lack of user and senior management involvement, poor project management, poor leadership skills and low response rate towards technology development [7]-[9]. The main source of failure of SDPs is the lack of soft issues or soft skills [10]. It is noted that $67 \%$ of software projects result in failure because of soft issues or soft skills [11].

Although it is noted that the majority of SDPs result in

Manuscript received July 25, 2014; revised January 7, 2015.

The authors are with University of South Africa, South Africa (e-mail: mtswees@unisa.ac.za). failure because of a lack of soft issues or soft skills, there is not much empirical research which has been conducted in the field of soft skills [3]. There are some researchers such as Stevenson and Starkweather [12] who conducted research in the field of soft skills but they were only working with a limited number of soft skills.

The main purpose of this study is to identify the soft skills that facilitate the delivery of a successful SDP. This paper will start by outlining the literature review, followed by the methodology for the study, the data analysis and results and finally a discussion, conclusion and recommendations for this study.

\section{LITERATURE REVIEW}

\section{A. Skills for Software Project Stakeholders}

People who are working within SDPs need to possess two sets of skills, namely soft skills and technical skills [13]. Soft skills are a cluster of sets of skills that influence the way in which people perceive, plan and execute tasks or duties within an SDP [2]. The research that was conducted by Stevenson and Starkweather [12] indicated that senior managers and company executives prefer soft skills compared to technical skills when appointing personnel. Their research indicates that soft skills are indeed important.

Technical skills are used when performing a particular task such as coding in an SDP. They are more important in ensuring that a technical task or duty is performed properly [13]. Technical skills are emphasized heavily in a classroom situation especially at universities or colleges and are given much attention in the field of research and also academia [2], [13]. Although they are given much attention, they are important but they are not sufficient to ensure the success of a SDP. They require soft skills to complement them [14].

SDPs use different stakeholders who are people that are involved in getting them executed, completed and making a decision whether they are successful or not [15]. These stakeholders require two sets of skills namely soft skills and technical skills. These two sets of skills have a positive impact on the job performance of an individual. A positive job performance of an individual has a positive impact in delivering a successful SDP [12].

\section{B. Causes of Software Project Failure}

The trend of failure of SDPs is the biggest challenge for industry and academics. It is noted that up to $70 \%$ of SDPs result in failure [16], [17]. The study conducted by Elmam and Koru [3] indicates that the top 5 causes of project failure are non-technical issues. These results support the claims that are made by researchers such as Noudoostbeni, Yasin and Jenatabadi [18].

Starkweather and Stevenson [10] further indicate that soft skills or soft issues contribute to the failure of SDPs. 
Noudoostbeni et al. [18] indicated that $67 \%$ of SDPs resulted in failure because of soft skills or soft issues. Although it is indicated that soft issues are one of the major sources of failure of SDPs, limited research work has being conducted regarding the role of soft skills within SDPs. Hence, there is a high demand for research in the field of soft skills, especially for SDPs in order to address their higher failure rate [2].

Although a previous researcher mentions that there is a high demand of research in the field of soft skills within SDPs, there are researchers such as Stevenson and Starkweather [12] who have already conducting it. The only weakness with their research is using a limited number of soft skills which are found in the advertisement for different roles in SDP teams for recruitment purposes. The people that require these soft skills are stakeholders that work within SDPs such as project managers [19].

\section{Different Stakeholders for Software Development Projects}

There is a wide variety of stakeholders in an SDP. Depending on different factors such as size, type and location, these stakeholders have one or more roles in a typical SDP. Stakeholders that are always part of any SDP are project manager, developers/programmers, end users, business analysts and quality assurers

Project managers play a vital role in ensuring the success of an SDP. They are able to influence the success of an SDP. They are responsible for ensuring that tasks and goals of SDPs are achieved. They are not able to do that on their own, but they rely on the people who work within the SDP. One of these groups of people are business analysts.

Business analysts are responsible for documenting the scope of work that needs to be done as part of an SDP. A business analyst basically translates the requirements of the users into technical specifications which can be understood by developers. Developers are responsible for coding the application or software based on the requirements that are documented by the business analysts. They translate the requirements of the users into the actual application using different technologies which are available for them.

After the developers are have completed their duties, they pass the actual developed application to quality assures. Quality assurers are responsible for ensuring that the application adheres to and addresses all the requirements that were stated by the users [20]. They are actually responsible for ensuring the quality of the application [21]. End users are there to provide direction of what needs to be done as part of the project [22] and they are the main reason why an SDP is conducted. The main purpose of conducting SDPs is to address the challenges the end users are facing [1]. The success of SDPs also depends on end users because they are the ones who are going to use the end product [15].

The stakeholders that are mentioned above need to posses different kinds of skills which will enable them to perform their tasks [11].

\section{The Difference between Software Development Projects and Other Projects}

SDPs are invisible, complex and flexible to develop and to integrate compared to traditional projects [23]. They also have a limited duration within which they need to be completed and also limited financial resources. The project team only exists for a certain period time of time for a particular purpose or to create an application which did not exist before [24].

SDP teams are human-centric activities which involve a lot of uncertainties [25]. Since they are human centric, it is vital for the members to have good soft skills. Another difference is the fact that the cost estimation for an SDP is conducted at the initial stages of the project [5]. The main challenge of that is the fact that some of the organisations overcharge and other charge too low and eventually discover that the work which needs to be done cost more than what they have charged.

Another difference is the fact that an SDP can be outsourced into different countries or continents altogether [26] or it can be developed in more than one country at the same time [27]. When they are conducted in different countries, additional challenges such as different cultures and time zones are introduced [27]. The main reasons why SDPs are often outsourced to international countries is because of lower costs, the availability of resources with the necessary skills, especially if it is a new technology, and also to speed up the development process of the application. It is noted that soft skills are more important than technical skills in a SDP [28].

\section{E. Theoretical Foundation of the Study}

The theoretical foundation for this study is based in the model presented in Fig. 1. The model shows that there are two job requirements for an individual who work in an SDP. Those requirements are soft skills and technical skills [2], [14]. Technical skills are used to perform tasks and soft skills are used for social purposes, especially interacting with the people who are working on the same SDP [14].

Technical skills and soft skills have an influence on the work behavior of an individual. Work behavior is the balance between technical skills and soft skills. It is a critical factor towards job performance [14]. According to research, job performance enables the software project team to deliver a successful SDP. Soft skills have an impact on the social aspects of a team member.

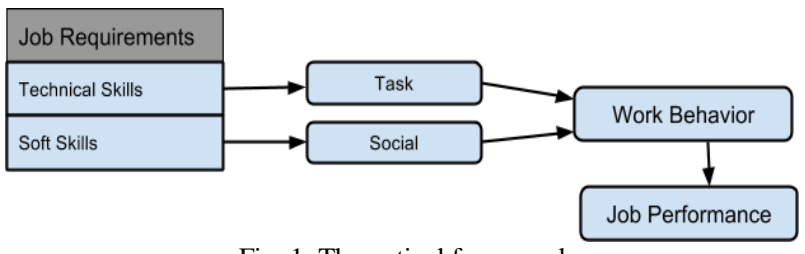

Fig. 1. Theoretical framework.

The main purpose of this study is to identify soft skills that contribute to the success of SDPs and to identify soft competencies that different roles within a software development team need to have. The roles that we are focusing on are business analysts, project managers, developers, quality assurers and end users. In order to achieve the objective of this study, the following research questions were identified:

Q1. Which soft skills in general contribute to the success of a software development project?

Q2. Which soft skills are important to different roles in facilitating successful software development projects? 


\section{METHODOLOGY}

The purpose of this study was to identify soft skills that facilitate the delivery of successful SDPs and soft skills for different roles within SDPs within the Gauteng province in South Africa. The soft skills that were used to develop a questionnaire were extracted from existing literature. This study was a quantitative research study which enables the researcher to collect numerical data [29]. A quantitative study also allows the researcher to analyze data using statistical software and to interpret the results [30].

\section{A. Population and Sampling}

The target population for this study were information technology professionals who work within the Gauteng province in South Africa and the users who provide direction for SDPs. Gauteng was chosen because is the economic hub of South Africa. Professionals that participated in this study were people who are working within SDPs and they were a combination of project managers, business analysts, developers, quality assurers and end users. End users were included because an SDP is conducted in order to address the challenges that they are experiencing and they are also vital for the success of an SDP. The participants of the study were based on their roles within SDPs.

This study used probability sampling where the sampling technique was purposive sampling. Purposive sampling allows the researcher to specify the roles or people who participate in the study [30]. A total of 110 invites were sent out using email. A follow-up email was sent to remind them to participate in the study. 60 responses were received which resulted into a response rate of $55 \%$.

\section{B. Data Collection and Research Instrument}

The instrument that was used for data collection was an online questionnaire. An online questionnaire was used because the geographic location is large and the researcher also wanted to avoid bias researchers may have when using interviews as the data collection instrument [31]. A link to the questionnaire was part of the email that was sent to the participants. Soft skills that were used to develop the questionnaire were collected from the literature and were reviewed by the professionals and senior academics. This was done in order to ensure reliability and validity.

\section{DATA ANALYSIS AND RESUlts}

IBM SPSS Software was used to analyze the data. Two types of quantitative analysis have been conducted, namely descriptive analysis and inferential statistics [32]. Descriptive statistics was conducted in order to gain a deeper understanding of the participants, and inferential statistics was conducted in order to address the research questions [33]. The following sections will present different statistical analyses that have been conducted starting with descriptive statistics and followed by inferential statistics.

\section{A. Descriptive Statistics}

The analysis shows that $37 \%$ of the participants were females and $63 \%$ were males. It also shows that $37 \%$ of the participants were business analysts, $23 \%$ were developers, project managers constituted $20 \%$ of the participants, quality assurers were $10 \%$ and the lowest number were end users $(8 \%)$. The age of the participants of this study ranged from 18 , with the oldest participant between the ages of 41-50 years of age. The majority of the participants were between the ages of 21-30 years of age. The smallest percentage of the participants was between the ages of 18-20 years.

The last descriptive statistics which was performed was the number of years of experience for different stakeholders. The results indicate that $50 \%$ of the participants have experience of less than 4 years. A small number of participants $(2 \%)$ have more than 20 years' experience.

The means for the different sections or categories of soft skills were calculated. The highest mean was 3.7 for communication and the lowest mean was 3.5 for team work. The final results of the calculation of means were used to compile Table I. The mean indicates that all different categories of soft skills are important towards delivering a successful SDP

\begin{tabular}{|c|c|c|c|}
\hline \multirow{2}{*}{ TABLE I: MEANS AND STANDARD DEVIATION } \\
\cline { 2 - 4 } & No. of items & Mean & Std. Deviation \\
\hline Communication & 60 & 3.7 & 0.28 \\
\hline Team work & 60 & 3.5 & 0.21 \\
\hline Leadership & 60 & 3.6 & 0.31 \\
\hline Attitude and behavior & 60 & 3.6 & 0.32 \\
\hline
\end{tabular}

The instrument that was used to collect data was a questionnaire. It is important for the researchers to test the statistical reliability and internal consistency of a multi-item Likert scale if it is measuring a construct. It is measured using Cronbanch's Alpha Coefficient [33]. The Alpha score for the entire instrument was 0.96 which indicates that is acceptable [34].

\section{B. Inferential Statistics}

This section addresses the research questions for this study.

Q1: General Soft Skills that contribute to the success of SDPs.

TABLE II: SOFT SKILLS BY ENTIRE POPULATION

\begin{tabular}{|l|c|}
\hline \multicolumn{1}{|c|}{ Soft Skills } & Percentages \\
\hline Team Player & 100 \\
\hline Personal Integrity & 100 \\
\hline Group work & 100 \\
\hline Time Management & 81 \\
\hline Effective Questioning & 80 \\
\hline Open Communication & 78.3 \\
\hline Critical Thinking & 76.7 \\
\hline Problem Solving & 73.3 \\
\hline Generating Feedback & 71.7 \\
\hline Planning and Control & 71.2 \\
\hline
\end{tabular}

In order to address the above research question, the researcher performed a cross-tabulation. The researcher chose only the top ten soft skills. The top three soft skills are team player, personal integrity and group work. Although some of the soft skills are not included, they are also important. The top ten soft skills are listed in Table II.

Team player and group work support the characteristics of an SDP team. SDPs are conducted in the form of teams which are comprised of individuals' different expertise [35]. Other soft skills that are also associated with SDPs are critical thinking and problem solving. Those two skills are 
also important because the team is solving the problem by creating a new product which did not exist before [36].

Q2: Soft Skills that facilitate the delivery of successful software projects by different roles.

The roles in this study are business analysts, project managers, developers, quality assurers and end users. Their results pertaining to soft skills are different from the results of the entire population. The soft skills that were rated very important towards facilitating delivering successful SDP projects by business analysts are compiled in Table III. The skills that are common with the ones from the entire population are team player, personal integrity, group work, effective questioning, critical thinking, generating feedback, time management and problem solving. The skills which were not regarded as important for business analysts are conflict management and listening skills. Having a greater number of soft skills that are common with the soft skills of the entire population is an indication that those skills are very important on different levels.

TABLE III: SOFT SKILLS BY BUSINESS ANALYSTS

\begin{tabular}{|l|c|}
\hline \multicolumn{1}{|c|}{ Soft Skills } & Percentages \\
\hline Team Player & 100 \\
\hline Personal Integrity & 100 \\
\hline Group Work & 100 \\
\hline Effective Questioning & 95.5 \\
\hline Listening Skills & 90.9 \\
\hline Critical Thinking & 90.9 \\
\hline Generating Feedback & 86.4 \\
\hline Time Management & 81 \\
\hline Conflict Management & 77.3 \\
\hline Problem Solving & 77.3 \\
\hline
\end{tabular}

The other role which is regarded important, especially in ensuring the success of SDP, are project managers. Project managers form an essential component of any project [37]. Listening skills, team player, group work and personal integrity were the top four soft skills rated by project managers. The common soft skills of the entire population and project managers that contribute to the success of software development are team player, personal integrity, group work and planning and control. Project managers value soft skills more than technical skills. According to the study conducted by Starkweather and Stevenson [10], senior managers prefer soft skills for project managers over technical skills. Skumoski and Hartman [38] identified problem solving, team player and effective questioning as the skills that are important for project managers. Refer to Table IV.

The other role which is critical towards the success of SDPs is software developers. Software developers are responsible for converting technical requirements into the actual end product which is the software application. There is no empirical research work which has been conducted on soft skills of software developers that the researcher is aware of. The top ten soft skills that facilitate successful SDPs according to software developers are listed in Table V. The top three soft skills for software developers are team player, personal integrity and group work. It is important for software developers to be good team players and to be able to function well within a group because SDPs are conducted in the form of groups and they usually constitute a large percentage of the entire team [39]. Time management, open communication, problem solving, critical thinking and listening skills are the skills that are usually used in an SDP.

TABLE IV: SOFT SKILLS BY PROJECT MANAGERS

\begin{tabular}{|l|c|}
\hline \multicolumn{1}{|c|}{ Soft Skills } & Percentages \\
\hline Listening Skill & 100 \\
\hline Personal Integrity & 100 \\
\hline Group work & 100 \\
\hline Team Player & 100 \\
\hline Conduct Meetings & 91.7 \\
\hline Planning and Control & 91.7 \\
\hline Ability to work under pressure & 91.7 \\
\hline Dependability and reliability & 90.9 \\
\hline Writing Skills & 83.3 \\
\hline Team Building & 83.3 \\
\hline
\end{tabular}

TABLE V: SOFT SKILLS BY DEVELOPERS

\begin{tabular}{|l|c|}
\hline \multicolumn{1}{|c|}{ Soft Skills } & Percentages \\
\hline Team Player & 100 \\
\hline Personal Integrity & 100 \\
\hline Group work & 100 \\
\hline Time Management & 80 \\
\hline Open Communication & 73.3 \\
\hline Listening Skills & 73.3 \\
\hline Problem Solving & 73.3 \\
\hline Critical thinking & 73.3 \\
\hline Trustworthiness & 73.3 \\
\hline Ability to work under pressure & 71.4 \\
\hline
\end{tabular}

When the developers have completed their part, the quality assurers need to test whether the work is properly done and whether it is of high quality. The top four soft skills identified for quality assurers are team player, personal integrity, group work and time management. The quality assurers ensure that the end users of the product will benefit from it. Refer to Table VI.

TABLE VI: SOFT SKILLS BY QUALITY ASSURERS

\begin{tabular}{|l|c|}
\multicolumn{2}{|c|}{ Soft Skills } \\
\hline Team Player & Percentages \\
\hline Personal Integrity & 100 \\
\hline Group work & 100 \\
\hline Time Management & 100 \\
\hline Open Communication & 100 \\
\hline Effective Questioning & 73.3 \\
\hline Managing Expectations & 66.7 \\
\hline Problem Solving & 66.7 \\
\hline Ability to work under pressure & 66.7 \\
\hline Flexibility and Adaptability & 66.7 \\
\hline
\end{tabular}

TABLE VII: SOFT SKILLS BY END USERS

\begin{tabular}{|l|c|}
\hline \multicolumn{1}{|c|}{ Soft Skills } & Percentages \\
\hline Team Player & 100 \\
\hline Personal Integrity & 100 \\
\hline Group work & 100 \\
\hline Open Communication & 80 \\
\hline Generating Feedback & 80 \\
\hline Listening Skills & 80 \\
\hline Time Management & 80 \\
\hline Trustworthiness & 80 \\
\hline Respectful & 80 \\
\hline Effective Questioning & 71.4 \\
\hline
\end{tabular}

The last role which was investigated in this study was end users. The end users were included in this study because they are the main reason why an SDP is conducted and will be the users of the end product [40]. They are also essential to the success of an SDP since they need to provide what 
needs to be done as part of the project [41]. The top ten soft skills that were identified by end users are listed in Table VII. The top three soft skills for this group are team player, personal integrity and group work.

The three common soft skills in all five roles that participated in this study were team player, personal integrity and group work. The three common soft skills conform to the characteristics of SDPs. SDPs are conducted in the form of teams, and the scope of the project is guided by the end user or the primary customer [41].

Although soft skills are important and complement technical skills, there are some of soft skills that were rated less important by different stakeholders. The skills that were rated less important by the entire population include politeness, sensitivity, self-promotion, observation and interviewing skills. Different stakeholders had different soft skills which were rated the least important.

The soft skills that did not have a high rating according to project managers were self-promotion, empathy, sensitivity and mentoring. According to business analysts these were politeness, observation, resilience, self-promotion, sensitivity, influence and persuasion. According to developers these were persuasion, observation, selfawareness, empathy, sensitivity and delegating. The quality assurers rated the ability to conduct meetings, selling skills, coordinating and facilitating skills low for the delivery of a successful SDP. The soft skills that were rated low by end users towards the facilitation of the delivery of a successful SDP were the ability to communicate at different levels, dependability and reliability, facilitating skills and observation.

\section{DISCUSSION, CONCLUSION AND RECOMMENDATIONS}

\section{A. Discussion}

Different soft skills are important towards facilitating the delivery of a successful SDP. Soft skills are there to complement technical skills. Technical skills and soft skills are equally important towards the facilitation of the delivery of a successful SDP [11]. Although soft skills are important, not all soft skills are equally important in facilitating the delivery of a successful SDP. This is indicated in the tables that show the soft skills for different roles. All the different roles have only three dominant common soft skills, namely team player, personal integrity and group work.

Different soft skills are important to different roles. The type of soft skills that are important depends on the duties of the different roles. There are some of the roles, such as software developers who rely heavily on technical skills to carry out their daily duties but that does not mean that soft skills are not important to them.

Different categories of soft skills are important as is indicated by the different mean values in Table I. The mean values indicate that soft skills in different categories are very important in facilitating the delivery of a successful SDP. It is important for different roles to have well-balanced soft skills in different categories. Different categories of soft skills as shown in table II are very important in facilitating the delivery of a successful SDP.

Although the study focused only soft skills, it does not mean that different roles should ignore the technical skills. Technical skills are also very important towards facilitating the delivery of a successful SDP.

\section{B. Recommendations}

Academic institutions should incorporate the development of soft skills into the curriculum. That will enable the students to have a well-balanced set of skills which combine soft skills and technical skills. The Project Management Body of Knowledge (PMBoK) guide [42] has been criticized for including only a small number of soft skills; the results of this study will provide the set of soft skills which people who are using PMBoK can incorporate into their standard. That will enable software development companies to improve the success rate of the projects they are delivering.

Academics and researchers should organise conferences where special sessions that focus on soft skills are incorporated. That will address the criticism of PMBoK by different researchers such as Pant and Baroudi [11]. The recruitment agencies or companies will have to incorporate a larger set of skills into their requirements when recruiting people for different roles. Organisations need to conduct more workshops for their employees for developing soft skills since academic institutions are equipping the candidates mainly with technical skills.

\section{Conclusion}

The purpose of this study was to identify the general soft skills that facilitate the delivery of a successful SDP. The results of those soft skills are compiled in table II. The second objective was to identify the soft skills that facilitate the success of soft skills by different stakeholders. The soft skills that were identified for different roles are compiled in different tables. The skills for business analysts are listed in Table III, for project managers in Table IV, for developers in Table $\mathrm{V}$, for quality assurers in Table VI and for end users in Table VII.

All the roles of people that participated in this study have different soft skills. The results indicate that different roles have different soft competencies which are vital to their work. There are a wide variety of soft skills, but they are not all equally important towards the facilitation of the delivery of a successful SDP.

This study was only conducted within a single province within South Africa; there is a need for a more comprehensive study that will cover the entire country. The results of this study can be used as a start for the development of a theory or model for soft skills that are required for the facilitation of the delivery of successful SDPs.

\section{REFERENCES}

[1] L McLeod and S. G. MacDonell, "Factors that affect software systems replicated development project outcomes: A survey of research," ACM Computing Surveys (CSUR), vol. 43, no. 4, 2011.

[2] F. Ahmed, F. Capretz, L. Bouktif, and P. Campbell, "Soft Skills and software development: A reflection from software industry," Journal of Information Processing and Management (IJIPM), vol. 4, no. 3. pp. 170-191, 2013

[3] K. E. Emam and A. G. Koru. (October 2008). A replicated survey of IT software project failures. Software IEEE. [Online]. 25(5). pp. 84$90 . \quad$ Available: http://ieeexplore.ieee.org/stamp/stamp.jsp?tp=\&arnumber=4602680\& isnumber $=4602659$ 
[4] S Sankhwar and D. Pandey, "Software project risk and assessment: A survey," Global Journal of Multidisciplinary Studies, vol. 3, no. 5, 2014.

[5] G. P. Sudhakar, A Farooq et al, "Soft factors affecting the performance of software development team," Team Performance Management, vol. 17, no. 3/4, pp. 187-205, 2011.

[6] P. Clarke and R. V. O'Connor, "The situational factors that affect the software development process: Towards a comprehensive reference framework," Information and Software Technology, vol. 54, no. 5, pp. 433-447, 2012.

[7] J. Y. Liu, H. G. Chen, C. C. Chen, and T. S. Sheu, "Relationships among interpersonal conflict, requirements uncertainty and software project performance," International of Project Management, vol. 29 no. 5 , pp. $547-556,2011$

[8] J. A. Starkweather and D. H. Stevenson, "PMP® certification as a core competency: Necessary but not sufficient," Project Management Journal, vol. 42, no. 1, pp. 31-41, 2011.

[9] L. J. May, "Major causes of software project failure," CrossTalk: The Journal of Defense Software Engineering, vol. 11, no. 6. pp. 9-12, 1998.

[10] J. A. Starkweather and H. S. Stevenson, "IT hiring criteria vs. valued IT competencies," Managing IT Human Resources: Considerations for Organizations and Personnel, 2011.

[11] I. Pant and B. Baroudi, "Project management education: The human skills imperative," International Journal of Project Management, vol. 26. pp. 124-128, 2008.

[12] D. H. Stevenson and J. A. Starkweather, "PM critical competency index: IT execs prefer soft skills," International Journal of Project Management, vol. 28. pp. 663-671, 2010.

[13] N. P. Napier, M. Keil, and F. B. Tan, "IT project managers' construction of successful project management practice: a repertory grid investigation," Information Systems Journal, vol. 19, pp. 255-282, 2009.

[14] S. Gillard, "Soft skills and technical expertise of effective project managers," Issue in Informing Science and Information Technology, vol. 6, pp. 723-729, 2009.

[15] T. Dingosoyr, S. Neur, V. Balijepally, and N. B. Moe, "A decade of agile methodologies: Towards explaining agile software development," Journal of Systems and Software, vol. 85, no. 6. pp. 1213-1221, 2012

[16] C. C. Chen, C. H. Chuck, and S. C. Yang, "Managing ERP implementation failure: A project management perspective," IEEE Transactions of Engineering Management, vol. 56, no. 1. pp. 157-170, February 2009.

[17] J. L. Eveleens and C. Verhoef, "The rise and fall of the Chaos report figures," IEEE Software, vol. 27, no. 1, pp. 30-36, 2010

[18] A. Noudoostbeni, N. M. Yasin, and H. S. Jenatabadi, "To investigate the success and failure factors of ERP implementation within Maysian small and medium enterprise," Information Management and Engineering, pp. 157-160, Kuala Lumpur, April 2009.

[19] K. Schwalbe, Information Technology Management, Cengage Learning.

[20] G. Grambow, R. Oberhauser, and M. Reichert, "Employing systematically driven adaptation for amalgamating software quality assurance with process management," in Proc. Second International Conference on Adaptive and Self-Adaptive Systems and Application, Lisbon, Portugal, 2010.

[21] L. J. Osterweil, "Toolpack - An experimental software development environment research," Engineering of Software, pp. 179-206, 2011.

[22] S. T. Acuna, M. Gomez, and N. Juristo, "Towards understanding the relationship between team climate and software quality - A quasiexperimental study," Empirical Software Engineering, vol. 13, no. 4, 2008.

[23] B. Hughes and M. Cotterell, Software Project Management, New Delhi, Tata McGraw-Hill, 2006.

[24] J. Pries-Heje and T. H. Commisso, "Improving team performance," in Proc. $33^{\text {rd }}$ Information Systems Research Conference in Scandinavia (IRIS), Rebild, Denmark, 2010, pp. 20-24

[25] A. Trendowicz, M. Ochs, A. Wickenkamp, J. Munch, Y. Ishigai, and T. Kawaguch, "Integrating human judgement and data analysis to identify factors influencing software development productivity," $e$ Information Software Journal, vol. 2, no. 1. pp. 47-69, 2008.

[26] C. Ebert and P. D. Neve, "Surviving global software development," IEEE Software, pp. 62-69, 2001.

[27] S. U. Khan, M. Niazi, and R. Ahmad, "Critical success factors for offshore software development outsourcing vendors: A systematic literature review," in Proc. Fourth IEEE International Conference on Global Software Engineering, 2009, pp. 207-216.

[28] S. C. Hsu and B. G. Mujuba, "Team Transformational leadership, trust, satisfaction and commitment: The testing of a structura equation model in software development team," Review of Business Information Systems, vol. 11, no. 3. pp. 17-28, 2007.

[29] J. Creswell, Research Design: Qualitative, Quantitative and Mixed Methods Approach, SAGE Publications, 2009.

[30] A. Bhattacherjee, Social Science Research: Principles, Methods and Practices, 2012.

[31] M. S. Olivier, Information Technology Research: A Practical Gude for Computer Science and Informatics, Van Schaik, 2009.

[32] R. D. K. van Ryzin, Research Methods in Practice, 2011.

[33] B. J. Oates, Research Information Systems and Computing, Cengage learning, SAGE Publications, 2009.

[34] J. R. A. Santos, "Designing a farm resume," Journal of Extension, vol. 37, no. 2, 1999.

[35] N. Ramasubbu and R. K. Balan, "Globally distributed software development project performance: An empirical analysis," in Proc. the ESEC-FSE'07, Dubrovik, Croatia, 2007.

[36] M. C. Weber and C. Wondrak, "Measuring the influence of project characteristics on optimal software project granularity," in Proc. ECIS, 2012.

[37] A. G. Crespo et al., "Software project managers under the team software process: a study of competencies," International Journal of Information Technology Project Management (IJITPM), vol. 1, no. 1, pp. 42-53, 2010.

[38] G. J. Skulmoski and F. T. Hartman, "Information systems project manager soft competencies: A Project Phase Investigation," Project Management Journal, vol. 41, no. 1, pp. 61-80, 2009.

[39] H. Kagdi, M. Gethers, D. Poshyanyk, and M. Hammad, "Assigning change to requests to software developers," Journal of Software: Evolution and Process, vol. 24, no. 1, pp. 3-33, 2012.

[40] P. K. Chilana, A. J. Ko, J. O. Wobbrock, and T. Grossman, “A multisite field study of crowdsourced contextual help: usage and perspectives of end users and software teams," in Proc. the SIGCHI Conference on Human Factors in Computing Systems, 2012, pp. $217-$ 226.

[41] U. Abelein, H. Sharp, and B. Paech, "Does involving users in software development really influence system success?" Software IEEE, vol. 30, no. 60, pp. 84-90, 2013.

[42] A Guide to the Project Management Body of Knowledge: (PMBOK Guide), Project Management Institute.

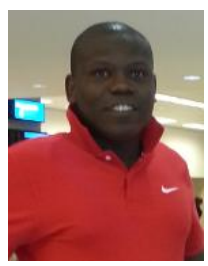

Emmanuel S. Mtsweni was born in South Africa. He lives in Johannesburg. He obtained the national diploma in IT in software development at the University of Johannesburg, South Africa. In 2010, he obtained the B.Tech. degree in information systems and technology management at the University of Johannesburg. He is currently a M.sc. student at University of South Africa. His research focus includes software development, software project management and IT management. He worked as a software developer.

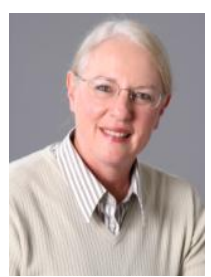

Tertia Hörne was born in South Africa. She lives in Pretoria, which is situated in the Gauteng province, South Africa. She obtained a B.Sc. degree in computer science from Rand Afrikaans University (now the University of Johannesburg). She did an Hon. B.Sc. degree, as well as an M.Sc. degree in computer science at the University of South Africa (UNISA). She was a senior lecturer at UNISA for many years teaching mainly computer architecture, assembly language and functional, as well as logic programming. She now works as an independent contractor for UNISA. Her research interests include formal methods, computer architecture and functioanl programming.

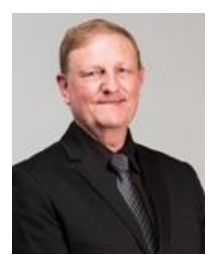

John Andrew van der Poll was born in South Africa and now lives in Gauteng, SA. He holds a $\mathrm{PhD}$ degree in computer science. He is a professor in ICT management at the Graduate School of Business Leadership at the University of South Africa, where he teaches courses in Business ICTs. His research interests are in formal specification techniques; automated reasoning; combining formal and semi-formal specification notations and the management thereof. $\mathrm{He}$ supervises numerous masters and doctoral students and has published widely in these areas. He leads a project aimed at determining the impact of Formal Methods in industry. 